\title{
CUMBRE MUNDIAL SOBRE EL DESARROLLO SOCIAL DE 1995: LA POBREZA EL DESEMPLEO Y LA INTEGRACION SOCIAL
}

\author{
Francisco Javier Ibisate S.J.
}

H ace mil años, al cerrarse el primer milenio de la era cristiana, cundió la noticia de que las profecías que anunciaban el fin del mundo cumplirían con su calendario. Se detuvo la actividad económica, las iglesias se llenaron de adoradores y penitentes y todos levantaban los ojos al cielo. Pasó el primer milenio, la tierra no se estremeció y la gente volvió tranquila a sus tareas domésticas. No hubo fenómenos naturales,pero el fin del milenio sirvió como un tiempo de reflexión, de conversión y de reconciliación. Ahora nos acercamos al límite del segundo milenio, y como las torres de las iglesias han quedado sumergidas entre los rascacielos de las sociedades de seguros, bancos y multinacionales no pensamos en que pueda venirse un fin del mundo; pensamos en el siglo XXI. Este es el título de algunos best-sellers: "Hacia el siglo-XXI" de Paul Kennedy; "La guerra del siglo XXI" de Lester Thurov, se puede añadir "Perestroika" de M. Gorbachov y "La tierra en juego" de Al Gore.

Estas obras esperan que entremos en el siglo XXI, pero también nos anuncian un fin del mundo "sui-generis", que no viene del cielo sino de los hombres y de la tierra. Es este fin del mundo "sui-generis" lo que las Naciones Unidas programan tratar en la Cumbre Mundial sobre el Desarrollo Social, del 6 al 12 de marzo de 1995, en Copenha- 
gue (Dinamarca). El camino hacia Copenhague:"Las sociedades prósperas son las que existen en función del ser humano".

Dados los aspectos multifacéticos a tratar, se integran en esta reunión el Banco Mundial, el Fondo de la ONU para la Infancia, el Programa de la ONU para el Desarrollo, la Conferencia de la ONU sobre Comercio y Desarrollo, el Fondo Internacional para el Desarrollo Agrícola y la Organización de la ONU para la Agricultura y la Alimentación. La próxima cumbre es parte integrante de las ocho conferencias organizadas por las Naciones Unidas en este decenio dedicado al desarrollo. La verdad es que nos cuesta leer y escribir sobre estos temas porque suficientes tristezas nos muestran los medios de comunicación social o nos han tocado sufrir personalmente. Incluso a los adultos nos pueden gustar las películas de dibujos animados porque suelen ser más humanizantes que las películas de veras. Pero la realidad está ahí, con todos sus claroscuros, y es esta realidad, la sociedad nacional y mundial, la que tenemos que analizar, comprender y salvar, porque hay millones de personas que cada día se aproximan a su fin del mundo.

\section{La agenda de la cumbre mundial}

ada nuevo y siempre nuevo como las hojas de nuestros ca
lendarios. Tres grandes temas: "La pobreza se ha generalizado. Disminuye el empleo productivo. Las sociedades se atomizan: los conflictos, las migraciones, los delitos, la violencia doméstica, la corrupción... No es tan sencillo cambiar de rumbo, pero se puede y se debe hacer..." (Documentos de antecedentes)

Los puntos de agenda no son nada nuevo sobre todo en un país que sale de unos Acuerdos de Paz, que acepta y que rechaza el informe de la Comisión de la Verdad, que monta comisiones para la corrupción y la violencia, que prorroga por un mes la constitución de una Corte Suprema de Justicia, que todavía tiene esperanzas de llegar a ser un Estado de Derecho. Al mismo tiempo hay muchas novedades en esta agenda. La primera novedad es que no está habiendo desarrollo sino discriminación. Que las medidas que utilizamos para medir el crecimiento económico esconden las mayores desigualdades. Que la economía es una ciencia social y la desfiguramos con cantidades sin cualidades. Que en los países desa- 
rrollados y en los subdesarrollados se está desarrollando la pobreza, el desempleo, los conflictos y las migraciones, los delitos y la violencia doméstica, así como la corrupción. Tan grandes como las diferencias son las similitudes entre países desarrollados y subdesarrollados. No es este "el fin de la historia" de Fukuyama. Nuestro pequeño mundo es una muestra representativa del mapa mundial.

\section{A) Las sociedades se atomizan}

Te aquí algunos datos del documento de antecedentes. "Los

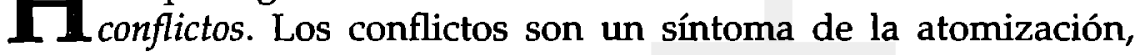
que desde 1945 ha cobrado más de 20 millones de vidas. En el decenio pasado creció el número de conflictos internos: de un total de 82 conflictos armados entre 1989 y 1992, 79 fueron intestinos, la mayoría de carácter étnico; el $90 \%$ de las víctimas fueron civiles. La migración. Los conflictos también producen refugiados y la migración forzosa. Tan sólo en 1993, un total de 6,8 millones de personas huyeron de tres países: Afganistán, la ex-Yugoeslavia y Mozambique. La migración misma ha pasado a ser un negocio. Según la Organización Internacional de las Migraciones, el contrabando de inmigrantes es a veces tan lucrativo como el tráfico de drogas. Los delitos. La cifra de delitos denunciados ha aumentado en una media anual de 5\% desde el decenio de 1980. Tan sólo en los Estados Unidos se cometen 35 millones de delitos anualmente. La escalada en el número de delitos cometidos es particularmente marcada en los países en desarrollo y en los países en transición; por ejemplo, el Ministerio del Interior de Rusia informó en 1994 que en el país operaban más de 5,600 pandillas, casi 10 veces la cifra correspondiente a 1990.

El tráfico ilícito de drogas representa ganancias anuales por un monto de $\$ 500.000$ millones, cifra equivalente al producto interno bruto combinado de las dos terceras partes de los Estados Miembros de las Naciones Unidas tomados en conjunto. Los sistemas de administración de justicia penal no están capacitados para enfrentarse con los tipos de delitos complejos y refinados, como la manipulación de los precios de las acciones, la especulación con información interna confidencial y el uso fraudulento de las tarjetas de crédito. La violencia doméstica. La violencia en el hogar es tanto un 
síntoma como una secuela de la disolución de los valores de la familia. Los niños son las víctimas de esta tragedia. También lo son las mujeres, que están en mayor peligro de morir a manos de sus parejas masculinas que de cualquier otra forma de asalto.

La corrupción. La corrupción pública ha pasado a ser un lugar común. En algunos países se calcula que los fraudes financieros representan un gasto equivalente al $10 \%$ del producto interno bruto. Estos son los sintomas de un mundo enfermo. Es preciso concebir un nuevo ideal de progreso social basado en la responsabilidad, la libertad y la solidaridad. Sin someter la paz a una "terapia intensiva" en forma de una nueva visión convincente del crecimiento económico, la protección ambiental, la justicia social y la democracia, todo en función del ser humano, esa meta podría eludirnos eternamente"... (Documentos de antecedentes)

\section{B) Crecimiento con subdesarrollo}

Wo hablamos del fin del mundo pero sí del advenimiento de to sin desarrollo, sino crecimiento con subdesarrollo humano. La pregunta es más fuerte: el crecimiento ¿se realiza a costa del subdesarrollo humano y ecológico? ¿Cómo se explica, sino, todos estos acólitos del crecimiento que se analizarán en la próxima Cumbre Mundial? Al neoliberalismo y a los programas de ajuste estructural ¿le preocupan estas heridas mundiales? Como indican los documentos de antecedentes, hemos pasado de una "guerrafría" a una "paz-fría". El juego de palabras merece unas palabras.

Las revistas de geoestrategia nos decían que si a finales de la década de 1970 se gastaban un millón de dólares por minuto en la carrera armamentística, la cantidad se había duplicado cuando se está escribiendo la Perestroika, donde M. Gorbachov lucha por detener la "manía armamentística". La disminución de los gastos militares desde que finalizó la guerra-fría arrojó un "dividendo de paz" potencial de unos \$ 935.000 millones entre 1987 y 1994. Con ello, según datos del Banco Mundial, su hubiera podido financiar un programa de servicios de salud para toda la población de los países en desarrollo, a un costo de $\$ 60.000$ millones por año: evitar más de 10 millones de muertes al año por enfermedades preve- 
nibles, y reducir en un $30 \%$ las enfermedades que afectan al mundo en desarrollo.

Pero la paz-fría es una "paz-violenta", a imagen y semejanza de la nuestra. Las armas convencionales y las disuasivas son mortiferas en clave-mayor: nos han habituado a contemplar con resignación - y a algunos con frialdad- las muertes masivas de inocentes, y también la lenta extinción de millones de personas. La parábola del buen samaritano se mundializa y junto al sentimiento de impotencia confesamos que hemos perdido los fundamentales valores humanos. Las guerras, la carrera armamentística y las luchas ideológicas nos han deshumanizado. Tal es la experiencia nacional donde encubrimos el informe de la verdad con la ley del olvido.

La guerra-fría profundizó también las crisis económicas. La onda larga descendente del Kondratief se resintió sensiblemente en los años 1970-1980-1989... En anterior publicación trasladábamos algunos titulares de la revista del FMI, 1992: "El comercio mundial registró el crecimiento más pequeño desde 1983"; "El crecimiento de la economía mundial sería del 1,5\% en 1992"; "Estudio de la OCDE prevé un aumento del desempleo en 1992"; "La hiperinflación en las antiguas economías de planificación central"; "Es necesario reforzar medidas que fomenten la recuperación económica mundial". "El déficit, el paro y la inflación crecen en la mayoría de los países desarrollados. La locomotora alemana creció sólo 1,5\% en 1992 y los "cinco sabios "pronostican un crecimiento cero para 1993". "Mala salud de hierro" era el calificativo que los analistas aplicaban a la economía de los Estados Unidos, que se niega a recuperarse de la recesión de 1990-1991; y el Time presenta en detalle la radiografía de la crisis..." (Realidad Económica-Social 1993 No. 31; pp. 49-50)

El acápite siguiente se titula: "Europa no es el hogar común". Como se presagiara en el Foro de la Sorbona (París, 1990) explotan los nacionalismos étnico-religiosos, la xenofobia, las avalanchas de emigrantes y los recelos del pobre oriental (Este) frente al opulento Occidente. Al igual que en la crisis de 1930 las grandes naciones se encierran en la política del sálvese el que pueda y hasta el Grupo de los Siete (G-7) siguen siendo siete: se juntan para dialogar y se enfrentan en el actuar internacional. A imagen y semejanza de 
lo que sucede en nuestro país, sólo que en octava alta, la crisis económica mundial ha desecado el espíritu de solidaridad. Incluso hay que preguntarse si el desarrollo y agresiva competencia de las multinacionales no están desmembrando las fronteras de las naciones políticas con un nuevo trazado de territorios económicos.

\section{C) La revolución tecnológica}

Como explica Xavier Gorostiaga S.J. en su artículo, "América Latina frente a los desafíos mundiales", la revolución tecnológica ensancha la brecha del Norte-Sur y la bipolarización del capital frente al trabajo. "Coincidimos con el historiador Paul Kennedy en que no ha existido en la historia de la humanidad un periodo en el que se dé tanta concentración, centralización e intensidad del capital en tan pocas naciones y en una población tan minoritaria. El Grupo de los Siete y el capitalismo central, con sus 800 millones de habitantes, controlan y hegemonizan más poder económico, tecnológico, informático y militar que el resto de los aproximadamente cuatro mil millones de personas que viven en Asia, Africa, Europa Oriental y América Latina, donde también una exclusiva minoría participa de las relaciones y estandar de vida del Norte. Esta concentración del capital corresponde al carácter de la nueva revolución tecnológica, donde el ciclo de acumulación del capital depende cada vez menos de la intensidad de los recursos naturales y del trabajo, para concentrarse en una acumulación tecnológica basada en la intensidad del conocimiento. La concentración y centralización del conocimiento tecnológico es más intensa y monopólica que las otras formas de capital, aumentando la brecha entre el Norte y el Sur..." (Realidad Económica-Social 1993 No. 34; pp. 383...) Esta breve referencia puede explicar el fenómeno de "crecimiento sin empleo", aunque la cita obedece más bien a la idea de señalar un nuevo factor aislacionista de la solidaridad y del enfrentamiento del capital trabajo, incluso al interior de los países industrializados. También nuestra Ley y Comisión de Ciencia-Tecnología pueden derivar en tensiones capitalistas.

$\mathrm{Al}$ pasar de la guerra-fría a la paz-fría se ha gestado otra modalidad de paz-violenta o dominación ideológica. La descomposición político-económica de los mal llamados "socialismos-reales" ha servido a sentar las bases de un neo-liberalismo que, olvidando los 
"Sentimientos Morales" de Adam Smith, impone las leyes del "corazón invisible" a continentes sumergidos en la pobreza interna y en la deuda externa. No hay economía sin empresas, sin precios y mercados, sin microeconomía, pero tampoco hay economía sin demanda y sin satisfacción de las necesidades humanas fundamentales. La cumbre mundial nos viene a recordar que no hay economía mundial, sino culpabilidad mundial en el debe y haber de los grandes sistemas económicos. La falsa superioridad neoliberal enfría todavía más el espíritu de solidaridad. Por ello, neoliberales, neosocialistas y los demás tenemos que retomar el capítulo tercero de Perestroika: “¿Cómo vemos el mundo actual? Hacia la Cumbre de Conpenhague".

Aparentemente en la agenda de esta cumbre no hay temas novedosos: la pobreza, el desempleo y la falta de solidaridad conviven en nuestro pequeño país y región. La gran novedad es que son problemas mundiales, que son problemas de "mayorías", de millones de personas. Lo sabemos por los diarios y la televisión, que también nos inyectan delirios por un consumismo insostenible mundialmente. Lo importante es pasar de los fenómenos, de lo que vemos, a la teoría, a la toma de conciencia. Si estos problemas son mundiales algo anda muy mal en el mundo, sean las teorías, sean las soluciones, sean los hombres. La gran novedad es que al cerrar el siglo- $\mathrm{XX}$ sigan existiendo estos problemas mundiales y que a los cien años haya que repetir "rerum novarum", algo nuevo. La raíz última, el pecado original, hay que buscarlo en la ausencia de solidaridad.

\title{
II. La pobreza se ha generalizado
}

\section{A) El agujero negro de la pobreza}

\begin{abstract}
Como se trata de presentar los documentos de antecedentes de la Cumbre Mundial citamos entre comillas o transcribimos las líneas y palabras claves de los mismos; creemos que esto da más autoridad y apoya lo que entre nosotros mismos decimos. Luego de un largo proceso electoral, con tantas proclamas y promesas, y testigos de tantas manifestaciones laborales, permitidas o no permitidas, parece necesario que en 1995 se sigan repitiendo las mismas estadísticas y recomendaciones que en 1994, 1993...
\end{abstract}


"En todo el mundo una de cada cinco personas, es decir, más de mil millones de personas ( 1.300 millones) vive por debajo del umbral de la pobreza... La cifra de los que padecen la pobreza extrema se cuadruplicará en el transcurso de una vida humana si se mantienen las actuales tendencias económicas y demográficas. Naciones enteras sufren las consecuencias: la deuda de los países en desarrollo es abrumadora. Al alcanzar los \$1,4 billones, casi duplica el monto de hace un decenio. El servicio de esta deuda implica egresos netos en efectivo del Sur al Norte y reducciones severas en los presupuestos sociales, lo que significa que los más pobres de la sociedad llevan el peso de esta carga..."

Al celebrar su medio siglo de existencia las Naciones Unidas observan que crecen a la par el entusiasmo desbordante del progreso material y la desesperación cada vez mayor de una pobreza inimaginable. Progreso material y pobreza inimaginables coexisten mundialmente, a veces codo a codo. Al primero y segundo mundo se añaden el tercero y el cuarto porque la pobreza sigue ganando terreno. La pobreza se hace sentir asimismo en los países ricos abatidos por la recesión, Tanto en los Estados Unidos de América como en los doce países de la Comunidad Económica Europea "cerca de un 15\% de la población vive por debajo del umbral de la pobreza". El fenómeno del "crecimiento sin empleo", sumado a los recortes presupuestarios en las esferas de los seguros y las prestaciones sociales, ha hecho crecer las filas de los desempleados y ha debilitado las redes de la seguridad social, especialmente entre las personas más vulnerables: las mujeres, los jóvenes, los ancianos y los discapacitados. Los efectos dramáticos de esta pobreza, dice el documento, se aprecia en los rostros de las zonas urbanas. "Cerca de un cuarto de millón de neoyorquinos, más del $3 \%$ de la población de esta ciudad y más del $8 \%$ de los niños negros han permanecido en refugios a lo largo de los últimos cinco años. En Londres hay registradas cerca de 400.000 personas sin hogar; en tanto que en Francia hay más de 500.000, de los cuales 10.000 están en París. Los bolsones de pobreza también se dan al interior del capitalismo progresista.

No es necesario agregar estadísticas sobre la lacerante pobreza del hemisferio subdesarrollado; para América Latina el número de pobres pasó de 112 a 184 millones de personas en la pasada déca- 
da. "Más del 70\% de los pobres del mundo son mujeres, seguidas de cerca por los ancianos". Boutros-Ghali ha expresado: "Son ellas también quienes, en las situaciones de miseria, de pobreza y de desintegración de las estructuras sociales, sacrifican su bienestar y en ocasiones su vida por mantener a su familia". El documento habla de "feminización de la pobreza" especialmente en el tercer mundo. Con las madres también son los niños las grandes víctimas de la pobreza. Algunas de las manifestaciones peores se encuentran en las áreas rurales, pero con el creciente hacinamiento en las villas-miseria y el fenómeno cada vez más extendido de los niños de la calle en muchas grandes ciudades, se tiene una mayor conciencia de la pobreza en los niños. La pobreza es presente y tiene futuro.

\section{B) Más población y más pobreza}

D e acuerdo a los cálculos del Banco Mundial si el crecimiento económico permanece bajo y continúan las tendencias crecientes en materia de pobreza, para el año 2.000 podría haber otros 200 millones de personas pobres en el mundo en desarrollo. También se ha dado un aumento sustancial de la pobreza en Europa oriental. A escala mundial se ha ampliado la diferencia entre el $20 \%$ de la población mundial situada en la escala inferior de los ingresos y el $20 \%$ que se sitúa en la parte superior. "Esa diferencia había pasado de una proporción de 1 a 20 en 1960, y de 1 a 60 en 1990. Dicho de otra manera, actualmente los más favorecidos -un $20 \%$ - recibirían el $83 \%$ del ingreso mundial, en tanto que los otros sólo obtendrían el 1,5\%."

El crecimiento acelerado de la población en los países en desarrollo (1,94\% anualmente) "hace muy difícil aumentar el nivel de vida y reducir la pobreza", dice Boutros-Ghali. Hay un temor creciente de que los efectos combinados de la pobreza, el crecimiento demográfico, las desigualdades económicas y sociales y las pautas de consumo derrochadoras constituyan un grave peligro para los recursos básicos de que dependerán las generaciones del futuro para su supervivencia y bienestar. El documento hace referencia a la correlación de pobreza y crecimiento de la población, tema que se está analizando estos días en la reunión de El Cairo, al parecer entre fuertes tensiones ideológicas por entrar en juego enfrentadas 
La pobreza se ha agudizado en el "decenio perdido"; la crisis de recesión en el mundo industrializado se ha hecho sentir en el estancamiento del flujo de donaciones. La deuda externa del tercer mundo acumula un monto impagable de \$1,4 billones, mientras que los $\$ 950.000$ millones gastados en el sector militar en 1990, representa la mayor sangría de recursos a fines pacíficos. La pobreza extrema lleva en gestación un "poder explosivo", afirma el historiador Paul Kennedy, comentando el estallido de la Revolución Francesa (S. XVIII). Más cerca de nosotros, Boutros Ghali señala: "Todo el mundo está de acuerdo en reconocer que la pobreza es moralmente escandalosa, económicamente nociva y políticamente peligrosa".

Las consecuencias de la pobreza entrañan que el mundo de los pobres quede excluido de los bienes, servicios, derechos y actividades que constituyen la base de la ciudadanía. Abandonando por un momento este documento, hay una expresión popular que en tres palabras refleja la condición del pobre: "uno de pobre..." Los puntos suspensivos dicen todo y basta darle vuelta a la frase: "el pobre no es uno, es nadie; nadie por uno". Es la mayor alienación y aislamiento.

\section{C) Pobreza y medio ambiente}

uien haya leído la obra de Al Gore,"La tierra en peligro", se
unirá al acuerdo general de que las naciones industrializadas Las naciones del ex-bloque soviético enfrentan hoy serios problemas de contaminación ambiental en tierra, mar y aire. Por su parte los países pobres, en su lucha diaria por subsistir, carecen a menudo de los recursos necesarios para evitar la degradación del medio ambiente. En la Conferencia de las Naciones Unidas sobre el Medio Ambiente la Primera Ministra de la India, Indira Ghandi, dijo: "la pobreza es el mayor contaminante", "La mayor parte de la población mundial vive en zonas de baja productividad agropecuaria y no tiene otra alternativa que seguir adelante con sus prácticas no sostenibles que harán más difícil que sus hijos salgan de la pobreza" (Boutros-Ghali). Por este motivo en la declaración de Río de Janeiro sobre el medio ambiente se solicita la cooperación 
multinacional para erradicar la pobreza como un requisito indispensable del desarrollo sostenible.

Los documentos de antecedentes explican la convocatoria a la cumbre sobre el Desarrollo Social porque los problemas multifacéticos de la pobreza, empleo y solidaridad, requieren soluciones multinacionales de los países ricos, de las instituciones financieras internacionales. El Banco Mundial (informe de 1990) ha formulado una estrategia de dos vertientes: "Una vertiente, que prevé la expansión del empleo y las oportunidades generadoras de ingresos entre los pobres, tiene que ver necesariamente con la naturaleza y el ritmo del crecimiento económico. La segunda vertiente en la estrategia del Banco Mundial, que consiste en fomentar la capacidad de las personas pobres para responder a las oportunidades que se presenten, busca ampliar el acceso a los sectores de la infraestructura social, tales como los servicios de la salud y la educación. Por ello pasamos a comentar los documentos de antecedentes sobre la situación del empleo en el mundo.

\section{La crisis del trabajo}

\section{A) El desempleo se globaliza}

$\mathrm{F}^{1}$ Secretario General de las Naciones Unidas enmarca el proble y crisis moral, que termina en una gran crisis de incertidumbre. "La atmósfera de incertidumbre afecta virtualmente a todas las esferas de la vida". Rememorando una expresión del pasado siglo, la mundialización de la economía y la desigual distribución de sus beneficios ha generado una polarización entre ricos y pobres que Boutros Ghali define como "darwinismo social".

De una población activa mundial de 2.800 millones de personas se calcula que un $30 \%$ - la mayoría en países en desarrollo- no tienen empleo productivo, y unos 700 millones se clasifican como sub-empleados. El flagelo del desempleo afecta incluso a la mano de obra de los países industrializados; las tasas de desempleo de la OCDE alcanza un promedio de $14,6 \%$, superando el $32 \%$ y $34 \%$ en Italia y España. Las tasas de desempleo entre los jóvenes del mundo desarrollado y subdesarrollado superan el promedio del 
desempleo general de la mano de obra económicamente activa. En ambos mundos, sobre todo en el subdesarrollado, la mujer es doblemente vulnerable: soporta desproporcionalmente la carga del desempleo y unos ingresos de $30-40 \%$ inferiores a los de su contraparte masculina.

\section{B) Crecimiento sin empleo}

Parecería que estamos retrocediendo siglo y medio cuando los nas que les despojaban de su trabajo. Los retos de la nueva tecnología y su concentración en las grandes transnacionales ha generado el fenómeno de la desaparición del mercado de trabajo y los efectos adversos del "crecimiento sin empleo". La crisis del trabajo es alarmante incluso en los países del Norte. El Grupo de los Siete (G-7) ha dedicado la reunión cumbre en Detroit (marzo de 1994) al tema del trabajo. Las estadísticas del desempleo a nivel mundial mostraban que la situación era aguda en la Unión Europea, donde en 1993 la producción se redujo en un 3,5\%, como consecuencia del desempleo, los bajos resultados y la falta de incentivos para estimular la competencia. Las elevadas tasas de desempleo en los países industrializados manifiestan que el mundo se enfrenta a un problema de reconversión productiva (cfr. Lester Thurow y Paul Kennedy), siendo una de las causales la transferencia obligada de producción y servicios armamentísticos a producción civil, así como la readaptación de la mano de obra activa adulta a las innovaciones tecnológicas.

Por lo que atañe a América Latina, la reciente Cumbre de Cartagena de Indias (junio,1994) dibuja en grandes pinceladas el claroscuro continental. Los desafíos que América Latina tiene planteados en este fin de siglo son la superación de las profundas desigualdades, el desarrollo democrático y la ubicación del continente en un orden mundial cambiante... "El ajuste se hizo por el lado del gasto, no de los ingresos, en recesión y no en crecimiento; donde hubo crecimiento fue crecimiento con grandes desigualdades. Se ha seguido exportando capitales, vía la fuga y el servicio de la deuda. Los estragos del ajuste allí están: más de diez años de estancamiento, recortes sin piedad del gasto social, desintegración de la infraestructura... La región se está desindustrializando, perdiendo em- 
pleo, sin encontrar el renglón donde sus factores le permitan ser competitiva. La apertura de mercados de consumo de clase media latinoamericana a la ola de productos provenientes de los Estados Unidos aumenta las contradicciones... El efecto-túnel de Albert $\mathrm{O}$. Hirschman encierra una combinación explosiva: una vasta pobreza, el sufragio universal y la ausencia de perspectivas desembocan sin falta en violencia e inestabilidad"... (El País, 20 de junio de 1994). Las propuestas o programas de desarrollo económico-social de varios de nuestros institutos de investigación recogen estos desafíos recomendando políticas de integración vertical interna y de integración geográfica regional, que ayuden a mejorar la cualidad técnica y competitiva de la producción interna y de las exportaciones no tradicionales. (Realidad 1994 N_35; pp. 303-343)

\section{C) Un colapso nervioso}

T a crisis del trabajo ha generado un "colapso nervioso a nivel - mundial", que se traduce en un extendido sentimiento de inseguridad, exclusión y desinterés social. Los desempleados crónicos, los jóvenes que no pueden encontrar trabajo y los inmigrantes que temen la expulsión y cuyos derechos se violan, viven en un permanente estado de ansiedad y de incertidumbre frente al futuro. Colapso nervioso, exclusión, inseguridad e incertidumbre se convierten en causales del considerable incremento del delito. Estos fenómenos se hacen más sensibles en las zonas urbanas por acumulación de población inactiva. Transcribimos antes dos datos escalofriantes: en los Estados Unidos se comenten 35 millones de delitos anualmente y el Ministerio del Interior de Rusia informa en 1994 que en el país operaban más de 5.600 pandillas, casi 10 veces la cifra correspondiente a 1990. "Azotada por la recesión, Europa, con sus fronteras recientemente abiertas, es particularmente vulnerable tanto a la falta del trabajo como al delito".

No es menester dar estadísticas sobre nuestro país porque el número de delitos dejan pequeñas las cifras que podamos adelantar. Lo que sí prueban todas las estadísticas es que nos enfrentamos al "fin de la historia" en un sentido muy distinto al que entendiera Fukuy hama, porque a nivel mundial no se ha dado realidad al Art. 23 de la Declaración Universal de los Derechos Humanos: "Toda persona tiene derecho al trabajo, a la libre elección de 
su trabajo, a condiciones equitativas y satisfactorias de trabajo, y a la protección contra el desempleo".

\section{D) Una agenda de medidas}

Si se da una interdependencia económica mundial debe darse a la crisis del trabajo y a sus consecuencias antisociales. El documento de antecedentes presenta tres grandes objetivos con sus respectivas políticas nacionales e internacionales. El objetivo de incrementar el empleo se traduce en tres medidas: cómo propiciar tasas más elevadas de crecimiento económica; cómo conseguir que el crecimiento genere empleo y cómo lograr un equilibrio entre la cantidad y calidad de los trabajos. El grupo de expertos y el informe del Secretario General sugieren la adopción de las siguientes medidas, cuyo contenido resumimos:

Crear oportunidades. Las posibilidades de empleo serán generadas ante todo por empresas individuales, privadas y cooperativas, de tamaño pequeño y mediano..., con apoyo gubernamental.

Estimular las inversiones especialmente de las empresas pequeñas y medianas, simplificando las normas y facilidades para el crédito... Apoyar las microempresas del sector no estructurado, hoy desatendido y sostén de unos 300 millones de personas en todo el mundo.

Propiciar el crecimiento mediante un marco jurídico apropiado, una política fiscal acertada, un entorno transparente y favorable a las inversiones, una legislación laboral no discriminatoria y la infraestructura necesaria... Este entorno es especialmente necesario en países en desarrollo, donde la mayoría de trabajadores ocupan empleos precarios.

Conseguir que el crecimiento genere empleo. Aunque no hay una cura milagrosa para el crecimiento sin empleo, la fiscalidad y el gasto público pueden en determinadas circunstancias emplearse eficazmente para estimular el crecimiento con empleo.

Adaptarse hacia el exterior. Una industrialización orientada hacia el exterior que catalice el crecimiento con empleo (cfr. Matrices intersectoriales). Realizar inversiones sustanciales en una mano de 
obra calificada; diversificar las exportaciones, adaptándose a los cambios del mercado mundial.

Prestar apoyo al sector de los servicios. La característica de las sociedades postindustriales ha sido el surgimiento de un dinámico sector de los servicios. Aunque los cambios tecnológicos pueden generar desplazamientos de la mano de obra, otros factores favorecen el crecimiento de empleos en el sector de los servicios: a) la generación de nuevos empleos gracias a la adopción de medidas de protección del medio ambiente; los servicios de atención de la salud y otros servicios destinados a los ancianos y a la expansión del mercado de viajes y el esparcimiento; b) La productividad y la remuneración crecientes en muchos empleos del sector de los servicios y, c) la renovación de contratos y la creación de nuevos puestos de trabajo, alentados por el fin de la recesión.

Mejorar los mercados de trabajo. En la esfera del empleo, las políticos de activación del mercado de trabajo deben incluir programas de apoyo al empleo por cuenta propia y a las pequeñas empresas, proyectos de obras públicas y actividades de desarrollo de la comunidad centradas en la creación de empleo. En la esfera de los ingresos, los gobiernos y el sector privado deben prestar apoyo a la capacitación en el empleo y el readiestramiento, a la movilidad geográfica de la mano de obra, y estimular la prestación de servicios de asistencia y apoyo (vivienda, transporte, guardería infantil...).

Invertir en educación. Además de necesaria resulta provechosa la inversión en educación, capacitación vocacional y aprendizaje, así como la capacitación en la empresa, de suerte que los empleados se adapten a las cambiantes necesidades tecnológicas.

Proteger a los grupos vulnerables. Son ellos los jóvenes, mujeres, ancianos, discapacitados, los trabajadores migrantes, indígenas y tribales, sometidos a largo tiempo de desempleo. Estos grupos marginados necesitan protección y medidas que les ayuden a encontrar un empleo remunerado.

Lograr un equilibrio entre la cantidad y la calidad de los puestos de trabajo. El empleo productivo y libremente elegido constituye el vínculo entre la creación de empleo y la mitigación de la pobreza. Una mano de obra saludable, motivada e instruida es fundamen- 
tal para el crecimiento económico.

Proteger los derechos de los trabajadores. Desde su fundación en 1919, la Organización Internacional del Trabajo ha hecho grandes contribuciones en la concienciación y formulación de convenios internacionales decisivos, ratificados por los Estados y referidos a condiciones de seguridad, higiene y aptitud del medio laboral.

Crecimiento con justicia. Este es el reto fundamental. La Cumbre por sí misma "no puede resolver los problemas de la pobreza, el desempleo y la desintegración social, pero debe ser capaz de generar el impulso político y la claridad de visión que permitan reforzar las medidas nacionales y la cooperación internacional mediante una renovada dedicación a mejorar la vida de las personas de todas las sociedades... "Colocar a los seres humanos en el centro del desarrollo sostenible".

Los programas de desarrollo nacionales deben aplicar políticas que se refuercen mutuamente en relación con: a) el crecimiento: promoción de un crecimiento sostenible elevado; b) la estabilidad: logro de la estabilidad macroeconómica con niveles elevados de empleo, equitativamente distribuidos; c) la eficacia en la aplicación de las políticas que estimulen el funcionamiento eficaz del mercado de trabajo; d) los incentivos: asignación equitativa de incentivos en apoyo de la productividad: e) la solidaridad: perfeccionamiento de las políticas económicas mediante el desarrollo humano. (Documento de antecedentes)

Por lo que atañe a nuestro país, los objetivos y políticas citados en estos documentos aparecen en las propuestas y programas de desarrollo económico-social, publicados o comentados en la fase preelectoral por diversas instituciones de investigación (IIES-UCA, CENITEC, FUNDE, FUSADES...), aunque no todos se inspiran en la misma filosofía económica. (Realidad Económica-Social 1993 N_35; pp. 495-524)

\section{Solidaridad: hacia una sociedad para todos}

\section{A) Las naciones desunidas}

T as vivencias de inseguridad e insolidaridad que impregnan $\downarrow$ nuestras conductas presentes son un reflejo del comportamiento 
mundial. El siglo-XX ha sido un productor de dos guerras mundiales y de más de un centenar de conflictos bélicos internos en los dos pasados decenios; la desgastante carrera armamentística, además de generar gravosos déficits en los erarios de grandes y menores naciones, se ha fundamentado en las más fiera y dogmática agresividad ideológica. El desarrollo se ha logrado a base de subdesarrollo y el mundo pasó de ser uno a ser cuatro. También en el siglo-XX se han repetido, con llamativa recurrencia, las ondas largas de expansión-contracción con que el economista ruso, N. Kondratief, describiera la historia oscilante del siglo XDX. Actualmente no acabamos de surgir de la seria contracción mundial de $1990 .$. Tres grandes flujos de capitales alimentan tres llagas de la humanidad: el comercio de armas, el narcotráfico y el servicio de la deuda, amén de la corrupción que circula dentro de cada país. Con las poderosas transnacionales resurgen reforzadas las trilaterales comerciales, donde se concentra el monopolio de la tecnología. Sumando y restando, una de las virtudes ausentes es la solidaridad, que tampoco encuentra su nido en los parámetros económicos del neoliberalismo triunfalista.

Este entorno mundial, donde hay otras luces y más sombras, explica la pregunta, $¿$ por qué una cumbre social? Yendo de lo macro a lo micro, a las calles de cada país, el Informe sobre el Desarrollo Humano de 1994, encargado por las Naciones Unidas, cita diez indicadores que ponen al descubierto el "debilitamiento del entramado social": homicidios, violaciones, divorcios, nacimientos fuera de matrimonio, hogares con un sólo progenitor, delitos relacionados con las drogas, suicidios, peticiones de asilo, número de prisioneros y el porcentaje de delincuentes juveniles en la población carcelaria. Todas estas cifras van en aumento, especialmente en los países de mayor desarrollo económico y en los países en transición. Ironía del siglo: desarrollo y deterioro social. Los gráficos y cuadros estadísticos son lacerantes. Aunque hirientes, algunos datos merecen la mejor reflexión.

\section{B) Síntomas de desintegración social}

Ge calcula que menos del $10 \%$ de la población total del mundo participa plenamente en las instituciones políticas, económicas, sociales y culturales que conforman sus vidas... El poder político 
sigue estando centralizado, sobre todo en el mundo en desarrollo, donde -como promedio- menos del $10 \%$ de los gastos nacionales se asigna a los gobiernos locales... Las mujeres constituyen el $66 \%$ de los analfabetos del mundo y el $70 \%$ de los pobres en el mundo... Se calcula que han desaparecido 100.000 mujeres de la población mundial (la mayoría en Asia Meridional y Oriental), donde después del sonograma se suele practicar el aborto de fetos femeninos... Las poblaciones indígenas, 300 millones en más de 70 países, suelen experimentar casos graves de discriminación y violencia... La dișcriminación racial se pone de manifiesto en la disparidad entre negros y blancos... Los Estados Unidos ocupan el primer lugar del mundo en violencia, con la incidencia más elevada de muertes (más de 12 por 100.000), violaciones notificadas (150.000 en 1993) y muertes infantiles por herida de armas de fuego (7.000 en 1992); otros tres millones de niños estadounidenses, aproximadamente, son víctimas crónicas de los maltratos y abandono. Los niños, en todas las partes, son víctimas vulnerables de la violencia... El asesinato de niños en Brasil aumentó en un $40 \%$ en un sólo año (1993-1994). En los centros de turismo sexual de Tailandia, Sri-Lanka y Filipinas trabaja un total aproximado de 500.000 niñas prostitutas.

Delito. Las actividades ilícitas van en aumento. En los Estados Unidos, solamente, en 1992 se notificaron 14 millones de delitos, que costaron al pais $\$ 425.000$ millones. Se considera que los gastos de los Estados Unidos en estupefacientes rebasan los ingresos (PIB) combinados de más de 80 países del mundo. A nivel mundial, muchos delitos tienen que ver con los estupefacientes; (se dan datos para varios países: Canadá, Australia, Dinamarca, Noruega, Japón...). Las organizaciones transnacionales que realizan actividades delictivas fuera de sus fronteras reciben ingresos por una suma estimada en $\$ 1.000 .000$ millones anuales.

Migración. Una de cada 115 personas del planeta es un migrante o refugiado que se ha visto obligado a abandonar su país por razones económicas, políticas o militares. Un millón de migrantes se trasladan del Sur al Norte cada año. La cifra de refugiados políticos y de víctimas de conflictos étnicos aumentó de 8 millones a fines del decenio de 1970 a unos 20 millones de personas... 
Conflictos. De los 82 conflictos ocurridos desde 1990, 79 ocurrieron dentro de las fronteras nacionales... (El caso de Ruanda transciende la imaginable; más del millón de muertos o desaparecidos). A principio de siglo, el $90 \%$ de las bajas causadas por la guerra eran militares; actualmente el $90 \%$ de las bajas se producen entre la población civil... Los gastos militares de los países desarrollados equivalen a los ingresos totales de los 2.000 millones de personas más pobres... En contraste, un adulto de cada cuatro es analfabeto y la quinta parte de la población mundial se queda sin comer cada día... (Documentos de antecedentes)

\section{C) Más allá de la paz-fría}

$\mathrm{Z}^{\mathrm{n}}$ verdad la guerra-fría nos ha empujado hacia una paz-fría,

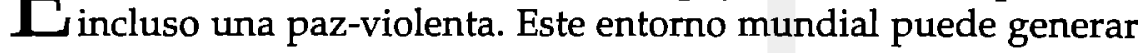
dos reacciones. La desilusión, el desánimo, la enclaustración, la teoría del fin del mundo. Este mismo cúmulo de datos que combinan la violencia con el sufrimiento, la riqueza y la pobreza, la maldad y la bondad, cataliza también la solidaridad con el sufrimiento, la pobreza y la bondad. Las antítesis pueden llevarnos a nuevas síntesis porque en el fondo somos seres humanos capaces de gestar un nuevo producto con toda esta aleación de luces y sombras. La solidaridad con el sufrimiento, la pobreza y la bondad existentes es creativa y es la solución para salvar la ecología humana. En un mundo de naciones desunidas la llamada a la solidaridad viene de las Naciones Unidas. El calificativo indica la solución.

Los documentos de antecedentes plantean a reflexión de las naciones participantes una líneas de acción a diversos niveles jerárquicos. El fin de la guerra-fría ha gestado un efecto desestabilizador. "Los países desarrollados han perdido la influencia que una vez ejercieron como objetos de competencia en la guerra-fría, y sus dirigentes afirman que no están suficientemente representados en las decisiones sobre comercio y finanzas internacionales. Entretanto las instituciones financieras internacionales $-\mathrm{y}$ una nueva organización del comercio mundial-- han asumido papeles más importantes en los asuntos mundiales, pero no han sido capaces de poner coto al deterioro económico en los países sumidos en la crisis, mucho menos de distribuir equitativamente los costos socia- 
les y financieros de sus economías nacionales"...

\section{D) El desarrollo: nuevo concepto organizador}

Se requiere un nuevo concepto organizador de estas institucioSnes internacionales que, abandonando la lucha anticomunista, conviertan su lema de manera que el mejoramiento de la condición de la vida de la gente y del planeta fuera el nuevo factor organizador de la vida internacional. La pregunta es, ¿quién planifica al planificador? Este es uno de los objetivos que busca la cumbre mundial: un nuevo concepto de desarrollo, encaminado a velar por la seguridad humana universal, basada en la equidad y sostenibilidad para esta generación y las generaciones futuras. " $\mathrm{El}$ desarrollo humano sostenible es un desarrollo que no sólo genera crecimiento económico, sino que distribuye sus beneficios equitativamente; regenera el medio ambiente en lugar de destruirlo; enriquece a la población en lugar de marginarla. Es un desarrollo que considera a los pobres como una prioridad, amplia sus opciones y oportunidades y prevé su participación en decisiones que afectan sus vidas. Es un desarrollo en pro de la población, en pro de los empleos y en pro de la mujer". James G. Speth-PNUD, Documento de antecedentes)

Sin ánimo de convertir la cita en una cuña publicitaria, sino de mostrar a modo de ejemplo la búsqueda de un nuevo concepto de desarrollo, se transcribe un párrafo del artículo, ¿Qué tipo de ciencia le sirve al desarrollo auténtico? Sin duda el lector querrá conocer el resto del artículo. "El desarrollo auténtico es una negación de la condición actual de empobrecimiento que gana gradualmente una concreta definición al negar las varias dimensiones del sufrimiento vivido por los pobres. (El concepto de desarrollo-auténtico introducido aquí fue tomado libremente de Goulet, 1998). Este representa una concepción de una vida amplia y floreciente, la negación de todas (o todas las más posibles) las dimensiones de sus sufrimientos, y una aspiración hacia un orden social en el cual lo normal son vidas libres y florecientes. Así, la manera en que se mide el desarrollo auténtico no puede ser progreso material (aunque requiere progreso material), y su motor no puede ser la innovación tecnológica relativamente independiente y no obstruyente. El desarrollo auténtico sirve como negación al sufrimiento sentido 
por la mayoría de la gente. Estos sufrimientos claramente envuelven una dimensión material la cual reiteradamente abruma nuestras conciencias; también tiene una dimensión social: el que la gente viva la destrucción de sus familias y comunidades, las necesidades de emigrar, el sentimiento de soledad; también tiene una dimensión cultural: cómo ellos perciben sus tradiciones, culturas, lenguajes, historias y ecologías destruidas; esto envuelve un sentimiento de impotencia y ausencia de recursos, a veces incluso un sentimiento de desmoralización, el reconocimiento de la ausencia de libertad en sus vidas, de que están sometidas a los empujones y tirones de fuerzas externas a su control (por culpa de la destrucción cultural y que se les niega el acceso a la educación) y a su entendimiento, que sus propias conciencias y conocimientos no importan en la historia; esto incluye la muerte precoz y dolorosa de sus hijos, las heridas del desempleo y del inestable empleo ocasional y la violencia sufrida por aquellos que actúan para cambiar". (Realidad 1994 N_39; pp. 372-373)

Otros agentes de la interdependencia son las empresas multinacionales que han alentado una rápida expansión de los mercados. Pero hay aspectos negativos en esta globalización. La asimilación de los nuevos gustos y aspiraciones transnacionales, en estilos externos de vida, genera también la pérdida de valores tradicionales y de la individualidad propiamente dicha. "La pérdida de solidaridad entre generaciones y de los vínculos que unen a las comunidades puede crear vacíos morales y culturales, y estos vacíos son el terreno propicio para la alienación y la conducta delictiva". Sobra decir que tales géneros de vida son insostenibles a nivel mundial, sobre todo a nivel del mundo en desarrollo.

\section{E) Los actores del desarrollo}

T a Cumbre Mundial pedirá "que haya una mayor cercanía en Ltre los gobiernos y la población", humanizando las burocracias y haciéndolas más responsables y más receptivas ante los ciudadanos; que garanticen las seguridad social general, promoviendo el crecimiento económico sostenible, aumentando el número de empleos productivos, garantice el funcionamiento de las redes de protección social y ayude a los desfavorecidos a mejorar su situación. Las recomendaciones de las Naciones Unidas coinciden con 
las políticas sociales y distributivas que vienen recomendando institutos de investigación y universidades de nuestro país: "el poder de redistribuir las cargas económicas y fiscales que puedan desalentar la diferenciación desorbitante de ingresos y ocuparse de sectores necesitados de la población por medio de programas sociales bien definidos. Por ejemplo, la fijación de impuestos progresivos, si no son excesivos, puede ser eficaz en la creación de incentivos socialmente favorables".

Los objetivos del verdadero desarrollo requiere la evolución de las funciones que corresponden al sector privado en el fomento de la integración social. "Han quedado atrás los días en que se podían establecer claras distinciones entre la función del gobierno y de las empresas privadas en la promoción del bienestar social y económico. Hay una necesidad cada vez mayor de crear asociaciones entre instituciones privadas y públicas para asegurar la calidad y la opción de bienes y servicios que requiere la población". Estas recomendaciones contravienen los fríos postulados económicos neoliberales, la dislocación del sector privado y público, así como la función subsidiaria y restringida del Estado. (Realidad N_38: 1994; pp. 164-181)

Los expertos reunidos en La Haya en 1993 dirigían las siguientes palabras a las empresas privadas del mundo desarrollado y en desarrollo: "Para sobrevivir, las empresas privadas tendrán que cambiar de un modelo basado en la elevación al máximo de las ganancias a un modelo que haga hincapié en la responsabilidad social y la rendición de cuentas a la comunidad. Valiéndose de las iniciativas del sector privado, el centro de atención del empleo productivo deberá desplazarse de la ganancia al ser humano". Estas palabras hablan también a los planes y programas de estudios universitarios en las ciencias económicas y empresariales.

Las recomendaciones finales buscan "una sociedad civil comprometida". Son los criterios y conductas de los grupos civiles que deben encarrilarse hacia la integración social. A este objetivo se convoca a las organizaciones no-gubernamentales, instituciones religiosas, asociaciones profesionales, sindicatos, cooperativas, grupos comunitarios y otras redes sociales que componen la sociedad civil. El documento agrega textualmente: “También pueden constituir un foro para que grupos de intereses diversos diriman sus 
diferencias en forma democrática y pacífica, con lo que se evitan conflictos y la posible desintegración de la sociedad". La recomendación cierra con un lema: "Nadie va por la vida sólo".

El último párrafo que citamos sirve a despejar los fantasmas con que se ha querido justificar nuestro largo conflicto civil y a centrar sus orígenes en las verdaderas causas. "La Conferencia de Población y la Cumbre Mundial se celebran en momentos de profundo recelo colectivo, en el que el fantasma de una tercera guerra mundial se ha visto sustituido por la incertidumbre de que la humanidad pueda sobrevivir a las consecuencias sociales y ecológicas del rápido crecimiento de la población, la producción y el consumo dispendiosos, y el militarismo... Es posible que en el futuro los conflictos surjan más bien dentro de las naciones que entre ellas, ya que sus orígenes están profundamente arraigados en las crecientes privaciones y desigualdades socio-económicas. La búsqueda de la seguridad en semejante entorno radica en el desarrollo y no en las armas"... (Documento de antecedentes)

Hasta aquí un extracto y recopilación de datos y comentarios emanados de estos documentos de antecedentes. La autoridad de las Naciones Unidas y de los expertos que han preparado la agenda de la Cumbre Mundial da mayor peso y vigencia a propuestas y programas de desarrollo que también emanan de varias instituciones nacionales. Vale la pena cerrar este comentario con algunas reflexiones domésticas.

\section{Reflexiones al pie de la cumbre mundial}

$A$ nte el poliedro multifacético de temas, desafíos y propuestas Ade soluciones que nos presenta esta Cumbre Mundial la dificultad mayor es ordenar algunas reflexiones domésticas, a sabiendas de que muchas de ellas se quedarán en el tintero. He aquí algunas, a modo de ejemplo, para que el lector las corrija y las complete.

\section{A) No maltratemos la pobreza}

F 1 último documento citado nos lleva a una primera reflexión a Equienes hemos convivido aquí las dos últimas décadas: los conflictos surgen más bien dentro de las naciones que entre ellas, 
ya que los orígenes están profundamente arraigados en las crecientes privaciones y desigualdades socio-económicas. Comencemos por recordar el uso de la gramática emocional; hay adjetivos demostrativos, posesivos y también los hay "mortíferos". "Capitalista" en la antigua URSS era sinónimo de Archipiélago de Gulag; "Comunista" entre nosotros ha significado lo mismo, sin archipiélago. De la gramática pasemos a la historia. Si rememoramos las décadas 1970-1980 — sin ir más atrás-a la pobreza y a los pobres se les ha maltratado con el "san-benito" de "comunistas-marxistas" y demás puntos suspensivos. En vez de aceptar el hecho de la pobreza material y marginación social de que incluso nos hablaban los Planes de Desarrollo 1960,1968,1973, con sus intentos de mínimas reformas estructurales (1976), en las elecciones trucadas de 1978 se lanza un plan militarista inspirado en la llamada "Seguridad Nacional". Se enmascaró a la pobreza con el fantasma del comunismo para legitimar una guerra que no nacía del Manifiesto Comunista sino de las entrañas del país. Baste repasar la Proclama de los jóvenes militares que dieron el golpe de estado en octubre de 1979, porque también ellos dijeron cuál era el verdadero origen de la conflictividad nacional. (Realidad Económico-Social 1993 N_33; pp. 229-230)

Con estas tergiversaciones se convierte en marxistas-leninistas a quienes simplemente tienen hambre y sed de justicia. En el Evangelio se califica esto como un pecado contra el Espíritu Santo por atribuye al mal espíritu lo que nace del Buen Espíritu; este pecado no se puede perdonar porque genera muertes sin límites, lleva a la muerte y no a la vida. En 1980 se asesina a Monseñor Romero, y antes y después a miles de inocentes. Cristianamente, este ha sido un gran pecado contra el Espíritu Santo; política y éticamente, la gran equivocación de algunos partidos gobernantes, sobre todo del partido que lo grita en su himno y convierte en estatua el derrame de sangre. Económicamente, la guerra hizo más pobres a los pobres y también dejó endeudado al Estado.

Qué caro nos ha costado en este país, y en otros, esta tergiversación de la pobreza para volver a reconocer, aunque no todos, en Chapultepec y en los Acuerdos de Paz la gran equivocación oficial: que la pobreza no es una ideología importada sino una criatura nacional. $Y$ ojalá que algunas instituciones y personeros del 
gobierno norteamericano, tan adelantados en tecnología cósmica, se pongan al día en la interpretación de la historia mundial y de las historias nacionales.

\section{B) El absurdo militarista}

$F^{1}$ absurdo militarista ha sido universal a lo largo del siglo- $X X$. Las guerras y la carrera armamentística han colmado el $50 \%$ de la producción mundial. Los erarios de las grandes potencias han quedado seriamente endeudados, sin que el FMI les aplique las correspondientes restricciones, y también las naciones pobres gastan proporcionalmente para empobrecerse. Todo nace de "la teoría de la coexistencia pacífica", que del Este pasa al Oeste y que tiene su raíz última en el antiguo adagio romano: "si vis pacem, para bellum" ("si quieres la paz, prepara la guerra"). Esto ha generado una ética al revés: la guerra es el camino para la paz y la paz justifica cualquier guerra. Las consecuencias no son sólo los montos desorbitantes de gastos militares. Las consecuencias son políticas, de dominación y de poder. Apartando las bambalinas que cubrían los verdaderos poderes en los regímenes del Este y del Oeste, nos encontramos con la misma trilogía: el partido político en el poder, (en el Este, uno y el mismo; Art. 6 de la Constitución), la jerarquía militar y la aristocracia económica del sector bélico-espacial. Todo ello fruto de la teoría de la coexistencia pacífica o cohabitación de contrarios. En este aspecto los sistemas opuestos no han sido tan opuestos y más bien parecen ser hermanos gemelos de distinto padre. En nuestros pequeños países la misma trilogía hace su nido: un partido minoritario, una jerarquía militar (antes hereditaria) y la aristocracia económica rigen los destinos de la nación.

Hay una tercera consecuencia que completa el absurdo militarista. En la economía de mercado se le enseña a la empresa a producir y servir a su majestad el consumidor. En la instrucción militar el consumidor último es el enemigo. Claro está que la finalidad escrita es la defensa del territorio y de la soberanía nacional, y a veces la seguridad interna. Para ello se exponen símbolos como la bandera, el himno, las fronteras y el cielo patrio. Pero toda la instrucción va dirigida a descubrir y describir al enemigo, y si la lente se empaña de ideología lo verde se convierte en rojo, termi- 
nando en serios accidentes nacionales. La disciplina, virtud cívica, suele petrificarse: las órdenes son verticales, en cascada e indiscutibles. La razón de las cúpulas es la razón ética, aunque el juicio de Nüremberg ya condenó este principio. Si la jerarquía militar se afilia a la teoría de la coexistencia pacífica y desfigura la tesis de la Seguridad Nacional, se convierte a miles de ciudadanos pacíficos en el consumidor final.

Es un dato digno de reflexión el aportado por los documentos de antecedentes: a inicio del siglo el $90 \%$ de los muertos en guerra eran militares; actualmente el $90 \%$ son civiles. Acostumbrarse, por oficio, a matar conciudadanos, en virtud de órdenes recibidas y peor si es por un instinto adquirido, transciende lo absurdo y se hunde en lo antihumano. Batallones de acción inmediata, cuerpos de seguridad, defensas civiles y mandos intermedios y superiores (valga lo dicho para ambos bandos) han polarizado la imagen de las instituciones militares. Grandes presupuestos para injustificados supuestos, que sí justifican la objeción y a los objetores de conciencia. Quien ha expresado más documentadamente estas realidades ha sido el informe de la Comisión de la Verdad, que sigue testificando en el informe del Grupo Conjunto. Siendo sinceros, junto con las fuerzas armadas tenemos que humanizarnos las fuerzas civiles, porque han sido civiles nacionales y extranjeros quienes educaron a las fuerzas armadas. $\mathrm{Y}$ el resto de civiles llevamos el militarismo dentro hasta cuando ejercemos el tráfico urbano o interdepartamental.

\section{C) Desarrollo del desarrollo}

os breves apuntes y referencias nacidos de los documentos de wantecedentes bastan a mostrar que estamos en la era de reformular las teorías y las políticas del desarrollo social. La cumbre Mundial dice en su frontispicio: "las sociedades prósperas son las que existen en función del ser humano". Desde aquí podemos deducir múltiples aplicaciones, a comenzar por los domésticos planes y programas de estudios universitarios, donde dicen que se forman los dirigentes del mañana. Sin duda el más cautivador "universitario" (de naciones y continentes) es el neoliberalismo de mercado, de mercancías más que de hombres. Su fe en la teoría del derrame vuelve a privilegiar a los de siempre y a decretar otro 
tiempo de espera a los indemandantes. Parecería que luego de la guerra fría hay un cambio de antorcha en la trilogía gobernante: la jerarquía militar le pasa la antorcha a la aristocracia económica y entramos en la fase de la paz-fría, con síntomas de paz-violenta.

Por ello la Cumbre Mundial sobre el Desarrollo Social convoca, junto con el Banco Mundial, a las instituciones financieras internacionales, a los gobiernos miembros y lanza una bengala iluminadora al sector privado empresarial para "cambiar de un modelo basado en la elevación al máximo de las ganancias a un modelo que haga hincapié en la responsabilidad social y la rendición de cuentas a la sociedad". Son todas estas instituciones quienes deben participar en esta reflexión. Por su parte, el neoliberalismo de los fríos ajustes estructurales debería prestar más atención a sus críticos que a sus aduladores, a los resultados más que a las profecías. También tenemos que decirnos unas palabras los críticos: que seamos críticos constructivos. A modo de médicos de la humanidad, porque las ciencias sociales son ciencias para los hombres, procuremos concretar las medicinas preventivas y curativas del subdesarrollo social. Primero, crear conciencia de estas realidades. Segundo, y para que lo primero no se quede en lo único, proponer alternativas realistas de desarrollo social, traduciendo en modelos y programas concretos las demandas que emanan de las mayorías populares. Es un consuelo que varios institutos de investigación, algunas universidades y bastantes agrupaciones sociales hayan hecho y sigan haciendo valiosos aportes constructivos, trazando sendas para el desarrollo. También es muy poco consolador que en otras instituciones similares no se haga vibrar el espíritu de solidaridad, sino el del propio crecimiento.

Las instituciones universitarias, centros de investigación y similares, verían sus esfuerzos multiplicados si los partidos políticos trasladaran estos avances a las esferas del poder. No todos los partidos hacen esta función de puente y en varios de ellos su comportamiento nos recuerda los fuegos artificiales: un poco de ruido, un poco de luz y luego saltan en pedazos. Por algo se llaman partidos. Sería muy triste que todos estos temas se discutan en las fases preelectorales y que luego se les embarque al centro del océano pacífico. 
Quienes permanecemos en el rodaje continuo del ciclo tras ciclo tenemos este serio compromiso. Los desafíos son tecnológicos y nuestras ingenierías pueden abrir caminos en el área de la cienciattecnología. Los desafíos son económico-empresariales, son jurídico-legales, son sociológico-grupales, son de incertidumbre-psicológica, son de educación-comunicación masiva, son filosóficos y son profundamente teológicos: en resumen son universitarios. Nuestra siembra de hoy es la cosecha del mañana y esta es la fe universitaria, aunque también estas cosechas están amenazadas por plagas y sequías. La "límbica" ley de educación superior pudiera animarnos en esta dirección: pero, primero habrá que despertar la ley allí donde esté archivada.

\section{D) Un epílogo optimista}

ada uno tiene derecho a recomendar su libro de cabecera. Los que vivimos la noche es más ancha que el día hay espacio para introducir la parte final del epílogo de "Perestroika", de M. Gorbachov, con la idea de levantar nuestros ánimos. Hay algo de anecdótico en el hecho de que el Secretario General del Partido Comunista de la URSS publica su obra en 1987 y en 1988 los norteamericanos le nominan "el hombre de los Estados Unidos". Algo de interesante debe haber en este libro.

"Los peligros que enfrenta la humanidad son muy grandes. Hay suficientes elementos de confrontación, pero las fuerzas deseosas y capaceş de detener y vencer esa confrontación están creciendo en poder y en su campo de acción, ante nuestros propios ojos. Deseamos ir de un movimiento de sospecha y hostilidad a la confianza; de un "equilibrio de miedos" a un equilibrio de razón y buena voluntad; de un nacionalismo egoísta y estrecho a la cooperación. Esta es la meta de nuestras iniciativas de paz y por eso continuaremos trabajando, sin descanso.

En el mundo hay una gran sed de mutuo entendimiento y comunicación. Se siente entre los políticos, adquiere impulso entre los círculos intelectuales, los representantes de la cultura y la opinión pública en general. Y si la palabra rusa perestroika ha sido fácilmente asimilada en el léxico internacional, se debe a algo más 
que interés por lo que sucede en la Unión Soviética. El mundo entero necesita reestructuración, es decir, desarrollo progresivo, un cambio fundamental. La gente lo siente y lo comprende. Tienen que encontrar su rumbo, captar el problema dominante de la humanidad, darse cuenta de cómo deben vivir en el futuro. La reestructuración es un imperativo para un mundo inundado de armas nucleares, para un mundo dominado por serios problemas económicos y ecológicos, para un mundo abrumado por la pobreza, el atraso y la enfermedad, por una raza humana que enfrenta ahora la urgente necesidad de asegurar su propia supervivencia.

Somos todos estudiantes y nuestro profesor es la vida. Creo que más y más gente va a darse cuenta que a través de REESTRUCTURAR, en el amplio sentido de la palabra, la totalidad del mundo mejorará. Si obtenemos buenas notas de nuestra principal maestra - la vida - entraremos en el siglo XXI bien preparados y seguros de que habrá posteriores progresos. Queremos que la libertad reine finalmente en todas partes del mundo en el próximo siglo. Queremos competencia pacífica entre diferentes sistemas sociales para desarrollar y alentar la cooperación mutua, antes que las confrontaciones y la carrera armamentística. Queremos que los pueblos de cada país disfruten de la prosperidad, la salud y la felicidad. Ese camino tiene su origen en un mundo no violento, libre de armas nucleares. Nos hemos lanzado por ese camino y llamamos a otros países y naciones para que sigan el ejemplo".

Comentar el epílogo sería estropearlo y baste añadir una casual coincidencia. A fines de 1987 un ruso, M. Gorbachov, y un polaco, Juan Pablo II, con un mes de diferencia, editan el primero la Perestroika y el segundo su encíclica "La preocupación social de la Iglesia". Para más coincidencia el capítulo tercero de Perestroika se titula: ¿Cómo vemos el mundo actual?"; y el capítulo tercero de la encíclica: "Panorama del mundo contemporáneo". Es alentador pensar que entre los políticos y entre los hombres de Iglesia hay una preocupación por el mundo actual.

\section{E) Una cascada hacia arriba}

To normal es que las cascadas caigan de arriba hacia abajo y así Lucede también con la ley de la gravedad política, económica y militar. Es un $10 \%$ quien toma las decisiones por toda la huma- 
nidad. Tal vez por eso la solidaridad no puede venir desde arriba, como tampoco lo hace la "fuente del derrame". La Cumbre Mundial del Desarrollo Social nos invita a hacer un invento novedoso para el mundo de hoy: hacer subir la solidaridad desde abajo hacia arriba. En nuestro mundo hay muchas fuentes de solidaridad. "A este objetivo se convocan a las organizaciones no-gubernamentales, instituciones religiosas, asociaciones profesionales, sindicatos, cooperativas, grupos comunitarios y otras redes sociales que componen la sociedad real". (Documento de antecedentes)

Lo más triste de nuestro mundo contemporáneo es que se han perdido o se están perdiendo los fundamentales valores humanos. Lo repetimos cada día cuando los medios de comunicación social agregan una nueva violencia al vaso ya desbordante de desgracias. Hasta tenemos miedo de convertirnos en seres insensibles y reaccionamos gracias al resorte de nuestra ética religiosa o humana. Esta lucha interna que libramos dentro cada uno de nosotros la sienten miles y millones de personas dentro y fuera de nuestras fronteras. Necesitamos el optimismo del epílogo de Perestroika y al "optimista" que lo escribió le debe mucho el mundo actual. Hay que pensar que las cumbres mundiales se asientan sobre las bases mundiales y que las crisis de valores generan antítesis de nuevos valores. Así nacieron nuestros Acuerdos de Paz y entre tropiezos y resbalones algo se ha avanzado en el descubrir y en el defender los derechos humanos. También nuestro gobierno ha dicho en El Cairo que está a favor de la vida; entre todos tenemos que enseñarle cómo hacerlo dentro del país, porque el informe de la Comisión de la Verdad sigue respirando.

Junto con la violencia y el crimen organizado, desde los Acuerdos de Paz también han emergido agrupaciones laborales, organizaciones no-gubernamentales, Iglesias en plural, institutos de investigación, grupos políticos (más que partidos propiamente dichos) y otros grupos populares de presión, además de organismos externos, analistas de los derechos humanos, que pueden hacer funcionar la cascada de la solidaridad de abajo hacia arriba. Cerrando el libro de cabecera, entre todos podemos empujar la tarea de la "perestroika", reestructuración, de la "glasnot", decir la verdad, y de la "novoye-mislenhive", asentar los nuevos principios o nuevas ideas "para mi país y para el mundo de hoy". 